\title{
How to Assess Breathlessness in Chronic Obstructive Pulmonary Disease
}

\author{
Hayley Lewthwaite (iD) 1,2 \\ Dennis Jensen (iD ${ }^{3-5}$ \\ Magnus Ekström (D) ${ }^{6}$ \\ 'School of Environmental \& Life Sciences, \\ College of Engineering, Science and \\ Environment, University of Newcastle, \\ Ourimbah, Australia; ${ }^{2}$ UniSA: Allied \\ Health and Human Performance, \\ Innovation, Implementation and Clinical \\ Translation in Health, University of South \\ Australia, Adelaide, Australia; \\ ${ }^{3}$ Department of Kinesiology and Physical \\ Education, McGill University, Montréal, \\ Québec, Canada; ${ }^{4}$ Research Institute of \\ the McGill University Health Centre, \\ Faculty of Medicine, McGill University, \\ Montréal, Québec, Canada; ${ }^{5}$ Research \\ Centre for Physical Activity and Health, \\ Faculty of Education, McGill University, \\ Montréal, Canada; ${ }^{6} \mathrm{Faculty}$ of Medicine, \\ Department of Clinical Sciences Lund, \\ Respiratory Medicine and Allergology, \\ Lund University, Lund, Sweden
}

\begin{abstract}
Activity-related breathlessness is the most problematic symptom of chronic obstructive pulmonary disease (COPD), arising from complex interactions between peripheral pathophysiology (both pulmonary and non-pulmonary) and central perceptual processing. To capture information on the breathlessness experienced by people with COPD, many different instruments exist, which vary in applicability depending on the purpose and context of assessment. We reviewed common breathlessness assessment instruments, providing recommendations around how to assess the severity of, or change in, breathlessness in people with COPD in daily life or in response to exercise provocation. A summary of 14 instruments for the assessment of breathlessness severity in daily life is presented, with 11/14 (79\%) instruments having established minimal clinically importance differences (MCIDs) to assess and interpret breathlessness change. Instruments varied in their scope of assessment (functional impact of breathlessness or the severity of breathlessness during different activities, focal periods, or alongside other common COPD symptoms), dimensions of breathlessness assessed (uni-/multidimensional), rating scale properties and intended method of administration (self-administered versus interviewer led). Assessing breathlessness in response to an acute exercise provocation overcomes some limitations of daily life assessment, such as recall bias and lack of standardized exertional stimulus. To assess the severity of breathlessness in response to an acute exercise provocation, unidimensional or multidimensional instruments are available. Borg's $0-10$ category rating scale is the most widely used instrument and has estimates for a MCID during exercise. When assessing the severity of breathlessness during exercise, measures should be taken at a standardized submaximal point, whether during laboratory-based tests like cardiopulmonary exercise testing or fieldbased tests, such as the 3-min constant rate stair stepping or shuttle walking tests. Recommendations are provided around which instruments to use for breathlessness assessment in daily life and in relation to exertion in people with COPD.
\end{abstract}

Keywords: dyspnea, dyspnoea, measurement, COPD

\section{Plain Language Summary}

Breathlessness is a dominant symptom limiting everyday life for people with chronic obstructive pulmonary disease (COPD), but often remains underreported and insufficiently assessed. The purpose of this paper is to review current and emerging methods to measure breathlessness in people with COPD - in terms of breathlessness severity or its change over time. Measurement properties and usefulness are compared for instruments between research and clinical settings. Standardized instruments and exercise tests are emerging to measure and compare relevant aspects of breathlessness between patients and in terms of the effect of treatment. Valid assessment is key to delineating the underlying mechanisms and to take forward improved evidence-based management of breathlessness. Recommendations on
Correspondence: Hayley Lewthwaite School of Environmental \& Life Sciences, College of Engineering, Science and Environment, University of Newcastle, Ourimbah, Australia

Tel +6I2 49854582 Email Hayley.Lewthwaite@newcastle.edu. au 
which instruments to use are provided for assessment in daily life and in relation to exertion in people with COPD.

\section{Background}

Breathlessness is a subjective experience of breathing discomfort with qualitatively distinct sensations that vary in intensity and emotional and behavioral significances. ${ }^{1}$ While in health, breathlessness is most commonly experienced during physical activity, for an estimated $9-11 \%$ of the adult population, breathlessness is pervasive with low levels of exertion or even at rest. ${ }^{2-4}$ Contributing factors to worsening breathlessness include advancing age, physical inactivity and deconditioning, obesity, pregnancy, anxiety, chronic cardiorespiratory disease, infections and malignancies. $^{2,4-8}$ One of the most common causes of breathlessness is chronic obstructive pulmonary disease (COPD). ${ }^{7,8}$

The majority of people living with COPD experience moderate to severe breathlessness in everyday life. ${ }^{9,10}$ In fact, activity-related breathlessness is the most problematic and disabling symptom of COPD, ${ }^{11-13}$ and is associated with impaired quality of life, ${ }^{14}$ reduced participation in daily activities ${ }^{15}$ and increased risk of hospitalization and early death. ${ }^{16,17}$ People with COPD in the community report having experienced breathlessness for $>10$ years, ${ }^{7}$ which has often persisted despite optimal management of the underlying cause(s) $)^{9,18}$ _ie, "chronic breathlessness", 19 COPD is also the primary underlying medical condition in an estimated $10 \%$ of people presenting to emergency care for episodic breathlessness, and is more common than other medical conditions like cancer or asthma. ${ }^{8}$ Acute breathlessness episodes occurring in the foreground of chronic breathlessness (ie, acute-on-chronic) further complicate breathlessness assessment and management. ${ }^{20,21}$

The pathophysiological mechanisms of breathlessness in COPD are complicated and multifactorial. Current evidence suggests the overall intensity of breathlessness is closely related to conscious awareness of increased inspiratory neural drive (ie, drive to breathe). ${ }^{22,23}$ When there is an imbalance between the inspiratory neural drive and the capacity of the respiratory system to increase ventilation (capacity to breathe), ie, neuromechanical uncoupling of the respiratory system, breathlessness sensations become particularly intense and unpleasant. $^{24}$ Breathlessness sensations depend not only on incoming sensory (afferent) information but also on how the individual centrally processes and interprets this information. $^{25,26}$ Past experiences, beliefs, and environmental cues collectively inform expectations around breathlessness, and influence the brain's prediction of what is happening in the body. ${ }^{25-27}$ Breathlessness can, therefore, be disproportionate to the level of underlying cardiorespiratory derangement when the individual relies on expectations rather than sensory cues to inform breathlessness predictions and perception. $^{26}$

The gold standard for breathlessness assessment is by self-report, using validated instruments that capture the appropriate aspects (dimensions) of the symptom. Given the complexity of breathlessness perception, simple physiological measures such as breathing frequency, peripheral oxygen saturation and forced expiratory volume in one second correlate poorly with breathlessness severity. ${ }^{28-30}$ Direct assessments of breathlessness may include assessment of the sensory (intensity, quality) and affective (immediate unpleasantness, fear, anxiety) dimensions. ${ }^{1}$ The sensory dimension encompasses the overall intensity of breathlessness as well as the distinct sensory qualities (work/effort of breathing, unsatisfied inspiration/air hunger, chest tightness), which are thought to arise from different underlying pathophysiological mechanisms and are associated with varying levels of unpleasantness and emotional and behavioral significance. ${ }^{1,31}$ Indirect breathlessness assessments capture information on the impact breathlessness has on daily life activities, emotional wellbeing and quality of life. ${ }^{1}$ Assessing the multiple aspects of breathlessness can provide insight into factors contributing to breathlessness, and identify potential therapeutic interventions better targeted to relieving the sensation. ${ }^{1,32}$

Despite the negative consequences of breathlessness for the individual and society at large, breathlessness often remains inadequately assessed and under treated. ${ }^{33}$ This may be because breathlessness is largely invisible at rest $^{34}$ and/or due to misperceptions that, beyond treatment of the underlying disease, "nothing more can be done". 33,35 Physicians may, therefore, avoid talking about breathlessness all together and the true impact of breathlessness remains hidden. ${ }^{34}$ To assess breathlessness, there are a plethora of available instruments and approaches, which differ in their scope of assessment and psychometric properties. Different instruments and approaches may assess the breathlessness experienced by an individual in daily life and/or the breathlessness response to an acute provocation stimulus, such as exercise. The specific 
assessment approach that best captures breathlessness depends on the context and purpose of the assessment.

The purpose of this paper is to review available breathlessness assessment instruments and provide recommendations around how to assess the severity of, and change in, breathlessness among people with COPD, in relation to daily life and in response to exercise. Breathlessness assessment instruments reviewed in this paper have predominantly been developed for English-speaking populations, based on English descriptors of breathlessness. The use and applicability of these instruments in linguistically and culturally diverse populations may differ from that of English-speaking populations, which tend to dominate the research field. The potential impact of language and culture should, therefore, be considered by the researcher or clinician who is assessing breathlessness with differences in how people experience and describe breathlessness likely to exist across populations.

\section{Breathlessness in Daily Life}

A number of different instruments are available to assess breathlessness in daily life for people with COPD. When selecting which instrument(s) to use in research or clinical practice, a number of considerations are to be made (Table 1). First, the researcher or clinician should consider the instrument's assessment scope. The instrument may be purpose-built with provision of different daily activities and the respondent indicates how participation in the activity is impacted by their breathlessness, or the respondent rates the severity of breathlessness experienced during the activity. This approach has the advantage of standardizing the reference activity type; however, respondents may not regularly participate in some (or all) of the reference activities and find it difficult to relate to their breathlessness experience. Alternatively, unidimensional rating scales such as the visual analogue scale (VAS) or numeric rating scales (NRS) may be used, where the respondent rates different breathlessness sensations during an activity or time period determined by the administrator. While this approach allows for individualization of breathlessness assessment, it makes comparisons across studies or timepoints difficult due to lack of standardization. Rating scales may be used as a unidimensional instrument, assessing a single dimension of breathlessness, or as part of a multidimensional symptom assessment.

Importantly, the choice of instrument to use should be based on its suitability for the intended purpose of assessment. The researcher or clinician assessing breathlessness may want to quantify the severity of breathlessness or its impact, or the change in breathlessness over time with disease progression or in response to a therapeutic intervention. For an instrument used to assess a change in breathlessness over time, its responsiveness (ability to detect change) and minimally clinically important difference (MCID) are important concepts. The MCID is the smallest change perceived to be important by the person. ${ }^{36}$ This can be determined using either an anchor-based approach, which compares the change in the instrument to a significant change in another relevant measure (anchor), or a distribution-based approach, which aims to calculate the MCID as a defined effect size or a standardized measure of between- or within-person variation. $^{37}$ Across different studies assessing change in health-related quality of life (HRQoL), MCID estimates were shown to approximate $0.5 \mathrm{SDs}$, which could relate to basic cognitive properties in the way people process and perceive sensations. $^{38}$

No matter the scope or purpose of assessment, the instrument used should be administered as intended by the developer (or as validated). Some instruments are designed to be self-administered while others require facilitation by a trained interviewer. Standardized instructions with pre-defined focal periods are provided with some instruments to assist with completion and ensure consistency across assessment occasions. Where standardized instructions are not provided, the administrator is required to provide an explanation to the respondent on how to complete the assessment, including the recall focal period.

An overview of commonly used instruments according to their scope of assessment is provided in the following sections and in Table 2. Detail is provided around psychometric properties for assessment of breathlessness severity or its change over time.

\section{Functional Impact of Breathlessness}

The physical limitation or functional impact of breathlessness can be assessed using the Medical Research Council dyspnea scale (MRC; or modified MRC $[\mathrm{mMRC}]^{39,40}$ which is more widely used), ${ }^{41}$ Dyspnea Exertion Scale (DES), ${ }^{42}$ Oxygen Cost Diagram (OCD), ${ }^{43}$ Baseline Dyspnea Index (BDI), ${ }^{29}$ or Disability Related to COPD Tool (DIRECT). ${ }^{44}$ The mMRC, DES and OCD each provide different daily activities of graded energy requirements and the respondent indicates when along the continuum they would be limited by their breathlessness. The $\mathrm{mMRC}$ is an ordinal 5-point scale with daily activities 


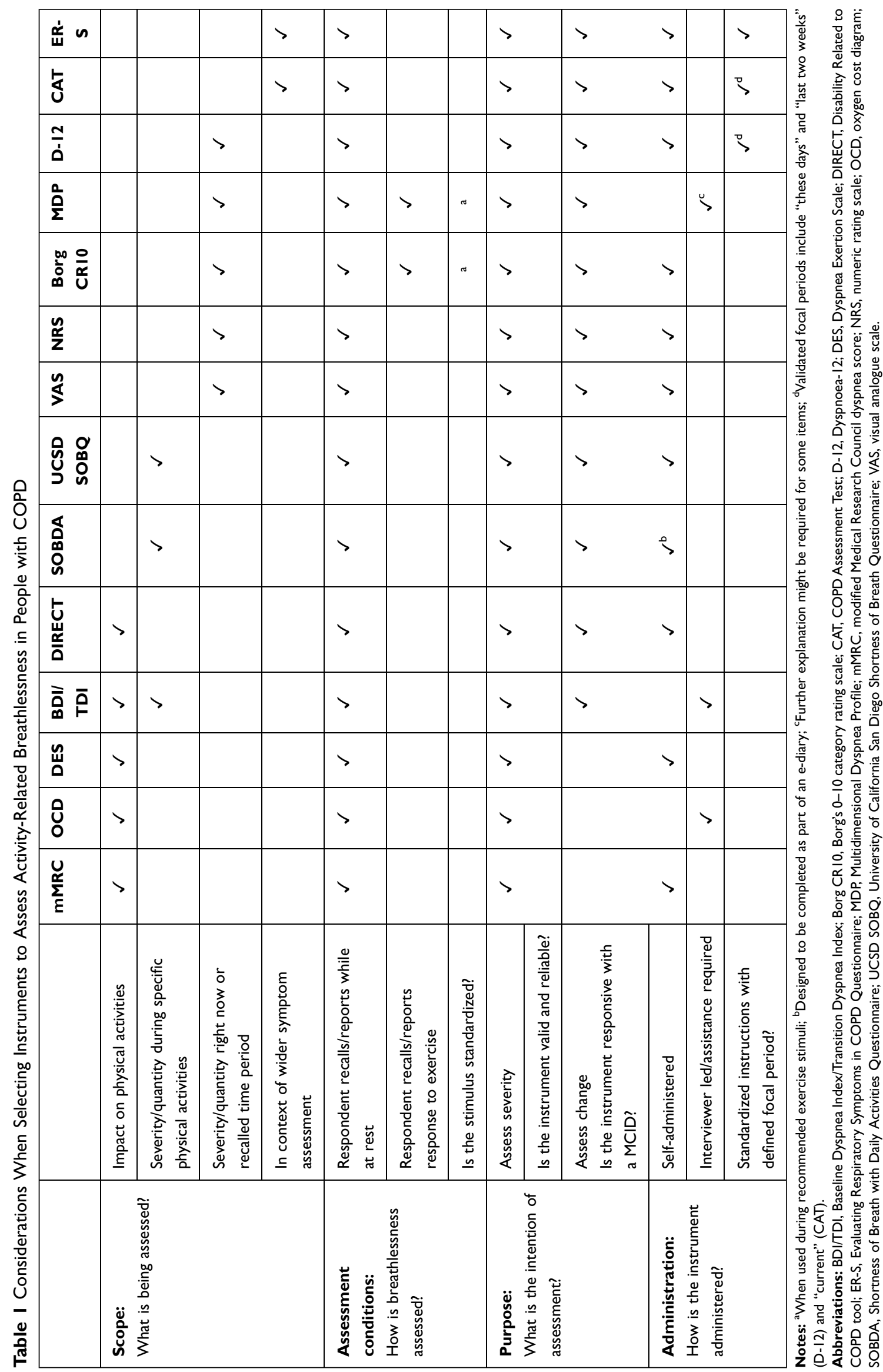




\begin{tabular}{|c|c|c|c|c|c|c|c|c|c|c|}
\hline 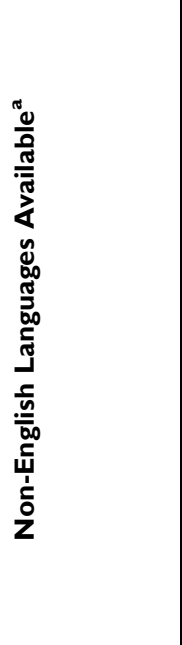 & 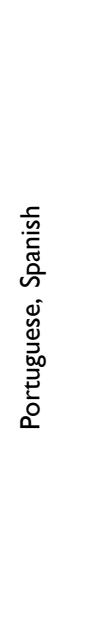 & 1 & $\begin{array}{l}\frac{c}{\underline{n}} \\
\text { 总 } \\
\text { in }\end{array}$ & 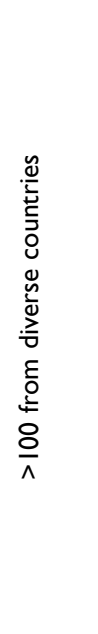 & 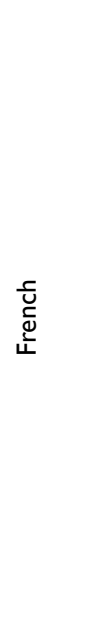 & 1 & 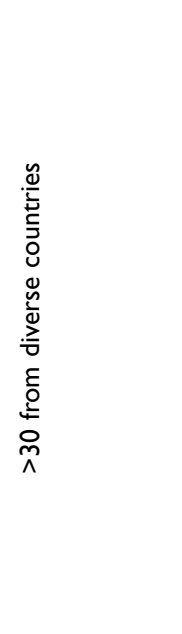 & 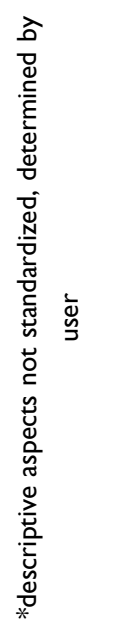 & 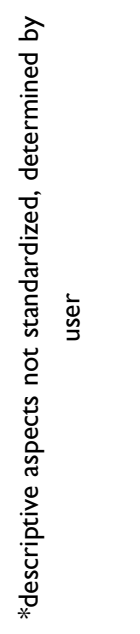 & 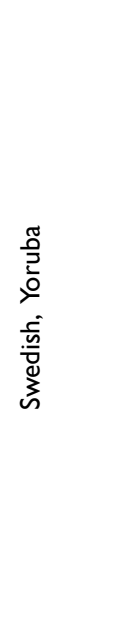 \\
\hline$\frac{O}{\bar{\Sigma}}$ & 1 & 1 & 1 & 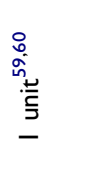 & 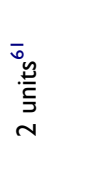 & 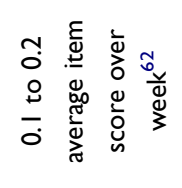 & 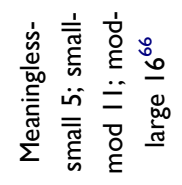 & 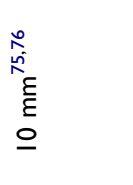 & 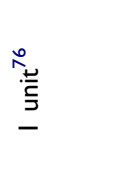 & $\begin{array}{l}\frac{\infty}{0} \\
\frac{0}{b} \\
\frac{.4}{5} \\
\underline{5} \\
-\end{array}$ \\
\hline & 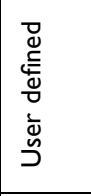 & 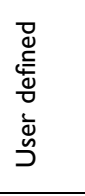 & 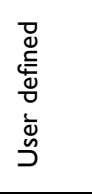 & 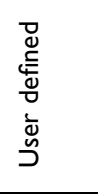 & $\begin{array}{l}\bar{g} \\
\overline{3} \\
\overline{3}\end{array}$ & 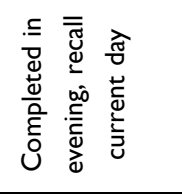 & 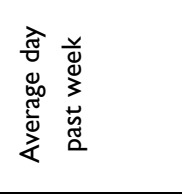 & 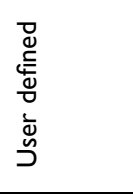 & 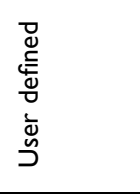 & 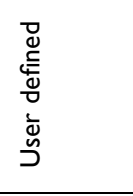 \\
\hline 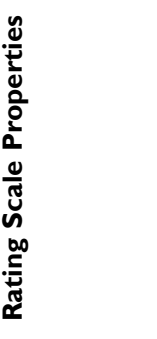 & 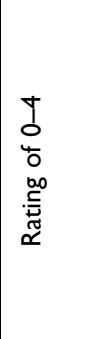 & 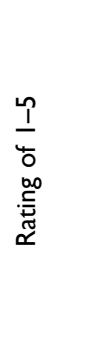 & 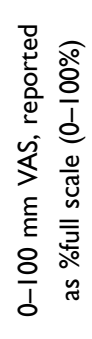 & 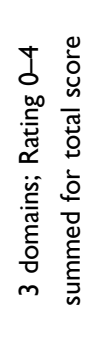 & 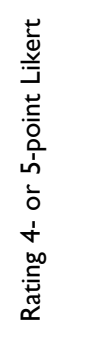 & 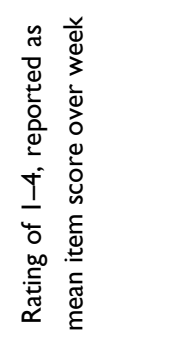 & 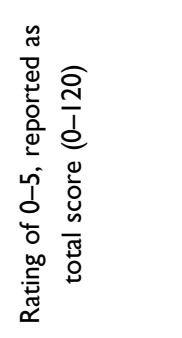 & 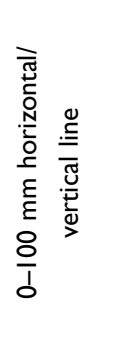 & 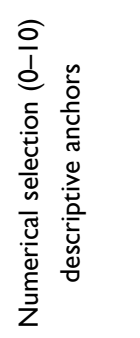 & 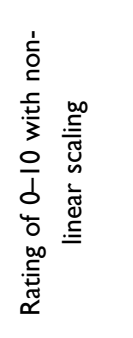 \\
\hline 胥 & & & & & & & & & & \\
\hline 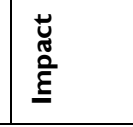 & & & & & & & & & & \\
\hline \multirow{2}{*}{ 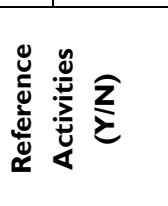 } & 离 & 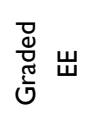 & 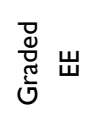 & 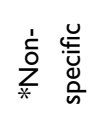 & 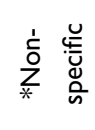 & $\begin{array}{l}\frac{m}{\bar{o}} \\
\frac{\vec{g}}{\underline{a}}\end{array}$ & 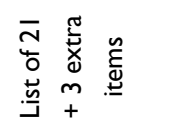 & 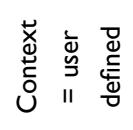 & 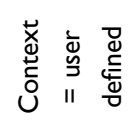 & 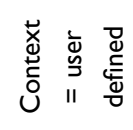 \\
\hline & $\succ$ & $\succ$ & $\succ$ & 艾 & $\succ$ & $\succ$ & $\succ$ & $z$ & $z$ & $z$ \\
\hline 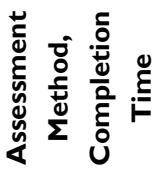 & 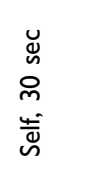 & 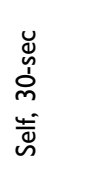 & 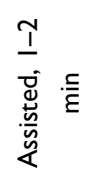 & 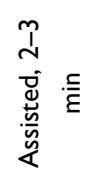 & 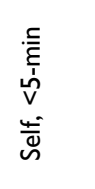 & $\frac{\stackrel{4}{\Phi}}{\infty}$ & 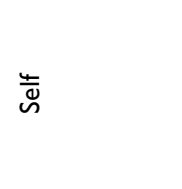 & 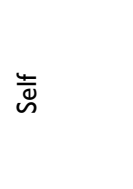 & $\stackrel{\frac{4}{\Phi}}{\stackrel{\infty}{~}}$ & $\stackrel{\frac{4}{\Phi}}{\mathscr{D}}$ \\
\hline 䒾 & 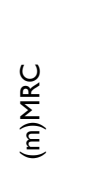 & 岀 & Oे & $\begin{array}{l}\overline{0} \\
\overline{0} \\
\text { o }\end{array}$ & 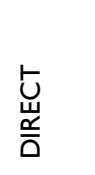 & $\begin{array}{l}\overleftarrow{o} \\
0 \\
0 \\
\infty\end{array}$ & $\begin{array}{l}\text { O్ } \\
\text { دે }\end{array}$ & $\frac{\tilde{x}}{5}$ & $\stackrel{\tilde{n}}{z}$ & $\begin{array}{l}\stackrel{0}{o} \\
\text { U. } \\
0 \\
\bar{o} \\
0\end{array}$ \\
\hline
\end{tabular}




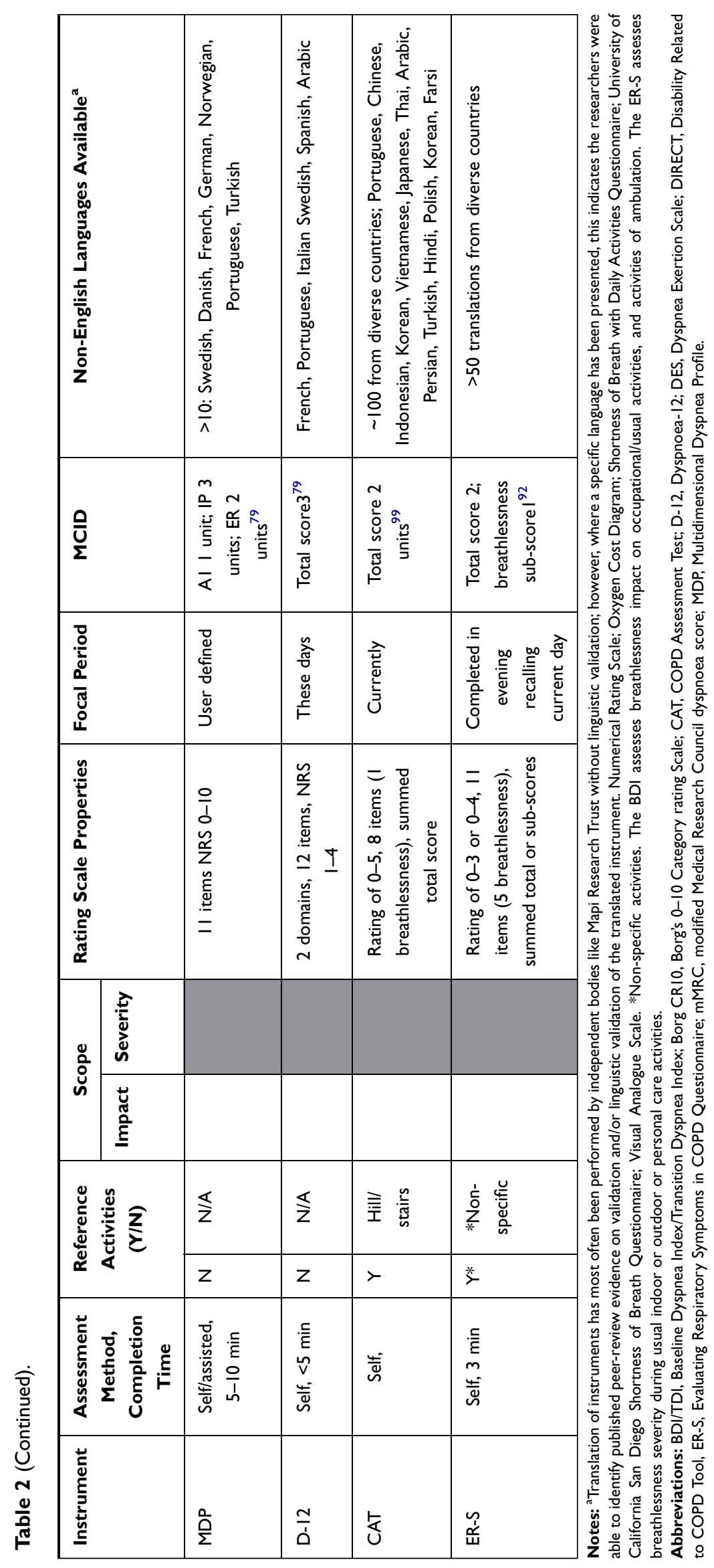


ranging from "I only get breathless with strenuous exercise" (score $=0$, or score $=1$ on MRC) to "I am too breathless to leave the house/I am breathless with dressing/ undressing" (score $=4$, or score $=5$ on MRC) ${ }^{39-41}$ The DES was developed to overcome a ceiling effect of the MRC observed in more severe disease populations. ${ }^{42}$ Daily activities range from "I am able to walk at my own pace on the level without getting out of breath" $($ score $=1)$ to "I am breathless at rest" $($ score $=5)$. The OCD is a $100 \mathrm{~mm}$ VAS with descriptions of daily activities at various points along the line from sleeping to brisk walking uphill. ${ }^{43}$ Participants indicate the point along the vertical line when their breathlessness would limit the activity from being performed; a percent full-scale score is calculated where $0 \%$ is maximal breathlessness and $100 \%$ is no disproportionate breathlessness.

In a similar way, the $\mathrm{BDI}^{29}$ uses a graded approach to assess functional impact due to breathlessness; however, there are three distinct domains with more generalized reference activities: 1) Functional Impairment, which assesses the level of impairment ( $4=$ no impairment to $0=$ very severe impairment) to usual activities and occupation due to breathlessness, with usual activities defined as "maintenance or upkeep of residence, yard work, gardening, shopping, etc.”; 2) Magnitude of Task, which assesses the level of ambulatory task ( $4=$ extraordinary to $0=$ no task) that elicits breathlessness (ie, from rest/sitting/lying to carrying heavy loads on the level/running); and 3) Magnitude of Effort, which assesses the level of effort (4=extraordinary to $0=$ no effort) associated with breathlessness (ie, from breathlessness while at rest/sitting/lying to only with greatest imaginable effort).$^{29}$ In each domain, respondents can also indicate if the amount of limitation is uncertain, information is unknown, or the limitation is due to other reasons than breathlessness.

The DIRECT ${ }^{44}$ contains 12 items to assess disability due to breathlessness, either how breathlessness limits participation in different daily tasks or how breathlessness impacts relationships. Respondents rate on a 4- $(0$ to 3 ) or 5-point ( 0 to 4 ) Likert scale how often the different daily tasks or relationships are impacted (eg, "never" to "all of the time"). A single total score is reported (0-34), with developers proposing that a score $>10$ indicates noticeable disability and $>20$ indicates high levels of disability. ${ }^{44}$

\section{Assessment of Severity}

The (m)MRC, DES, OCD, BDI and DIRECT are valid and reliable instruments for assessment of the functional impact of breathlessness. ${ }^{44-48}$ In people with advanced COPD and other causes of severe breathlessness, the DES may be more appropriate, shown to have slightly better concurrent validity (with NRS assessment of breathlessness severity) compared to the mMRC. ${ }^{42}$

These instruments are low cost (freely available), easy to administer and easy to interpret. ${ }^{49}$ The mMRC is able to be completed by respondents independently in around 30 sec. ${ }^{39}$ The BDI, which was designed to be interviewer led, takes 2-3 minutes to complete. ${ }^{39}$ The OCD might be more difficult for respondents to understand and requires further explanation by an interviewer; however, it can be completed in under 2 minutes. ${ }^{39}$ The DIRECT can be completed independently by participants in less than five minutes. ${ }^{44}$ Notably, the mMRC and BDI provide important clinical information, significant independent predictors of $1^{50}$ and 5-year mortality in people with COPD. ${ }^{51-54}$ In fact, in people with COPD, a single study reported the $\mathrm{mMRC}$ to be a better predictor of premature death than forced expiratory volume in $1 \mathrm{sec} .^{53}$ For this reason, international guidelines for COPD management recommend use of the mMRC to help categorize COPD burden and guide management. ${ }^{55}$ Less prognostic information is available on the OCD; however, the OCD shows moderate to strong correlations with the $\mathrm{BDI}^{46}$ and the two instruments show similar correlations with different physiological (arterial blood gas) and HRQoL measures. ${ }^{46,56}$

\section{Assessment of Change}

The MRC, DES and OCD have not demonstrated responsiveness for measuring change and there are no established MCIDs. ${ }^{42,57,58}$ The lack of responsiveness of the mMRC and DES may be due to being unidimensional with relatively few and broad categories available for selection. ${ }^{42}$ In contrast, the BDI was designed to assess change in breathlessness over time in people with respiratory disease with the use of the accompanying Transition Dyspnea Index (TDI) ${ }^{29}$ The TDI is used to rate a change in each of the three BDI domains over time on a 7-point scale from "major deterioration" $=-3$ to "major improvement" $=3$. The final TDI score, therefore, ranges from -9 to 9 . The TDI is responsive to pharmacological intervention in people with COPD, with an established MCID of 1 unit. $^{59,60}$ The DIRECT has also recently demonstrated to be responsive to pulmonary rehabilitation with a MCID of $\geq 2$ units. $^{61}$ 


\section{Breathlessness Severity with Daily Activities}

The Shortness Of Breath with Daily Activities (SOBDA) questionnaire $^{62,63}$ and the University of California San Diego Shortness of Breath Questionnaire (UCSD SOBQ) ${ }^{64}$ provide a list of common daily activities and the respondent rates the severity of breathlessness during each activity. The SOBDA is intended to be completed by respondents as an e-diary in the evening, listing 13 different activities with a choice of five options to indicate the severity of breathlessness during each activity that day from "not at all" $=1$ to "so severely that I did not do the activity today" $=4$, or an option to indicate that the activity was not performed (=missing). The mean of the scores over all activities is the final score; however, the mean weekly SOBDA score has been shown to be more stable and informative than the mean daily score. $^{62,65}$ The UCSD SOBQ lists 21 activities, and the respondent rates the severity of breathlessness during the activity on an average day over the past week from $0=$ not at all to $5=$ maximal, or unable to do [the activity] because of breathlessness for a total score of 0-120. If the respondent does not usually do the activity, they are asked to anticipate how breathless they would be if they were to do the activity. Three additional items assess the impact of breathlessness, fear of harm from overexertion, and fear of shortness of breath.

\section{Assessment of Severity}

The SOBDA and UCSD SOBQ have both demonstrated good test-retest reliability, high internal consistency, discriminative ability across the COPD disease spectrum, and good convergent validity when compared to measures of HRQoL and exercise capacity (eg, six-minute walk distance, UCSD SOBQ only). ${ }^{48,62,64,65}$

\section{Assessment of Change}

In people with COPD, the SOBDA and UCSD SOBQ have shown to be responsive to pharmacological intervention and lung volume reduction surgery, respectively. ${ }^{62,66}$ The MCID for the SOBDA has been estimated at 0.1-0.2 for average item score over a week, ${ }^{62}$ while the MCID for the UCSD SOBQ has been defined in thresholds of meaningless to small change $=5$, small to moderate change $=11$ and moderate to large change $=16^{66}$

\section{Unidimensional Rating Scales}

Intensity overall or of individual breathlessness dimensions can be measured using unidimensional rating scales, such as a VAS, NRS or Borg's 0-10 category ratio scale
(CR10). ${ }^{67,68}$ The NRS and VAS both use linear scaling anchored by extreme descriptors of breathlessness often defined by the user; for example, "no breathlessness" to "the worst breathlessness ever experienced". The NRS displays numerical values, often 0 to 10 , that separate the two extreme descriptors. The VAS presents a horizontal or vertical $100 \mathrm{~mm}$ line without numerical values. The Borg CR10 scale has nonlinear scaling of numerical values labelled with descriptors, with the exception of six and eight. Descriptors range from "nothing at all" $=0$ to "maximal" $=10 .{ }^{67,68}$ Respondents may bias ratings towards the values with labels, and therefore the explanation provided to respondents should indicate that they are to "choose a number to describe your breathlessness". ${ }^{69}$ Since the original Borg CR10 scale, ${ }^{68}$ a number of iterations have been published with modifications to the verbal descriptors. In 1982, Burden et $\mathrm{al}^{70}$ modified the CR10 scale for assessment of breathlessness in people with asthma, numerical descriptors were modified from, for example, "very, very slight" to "extremely weak" for a rating of 0.5 and from "very, very strong" to "very, very severe" for a rating of 9 . Kendrick et al in $2000^{71}$ again modified the Burden et al version to include the term breathlessness in the verbal descriptors (eg, very severe breathlessness for a rating of 7).

\section{Assessment of Severity}

The NRS and VAS are valid and reliable for assessment of breathlessness severity in COPD, and ratings between instruments are highly correlated when assessing severity of breathlessness "right now". ${ }^{72,73}$ The $0-10$ NRS may be easier for people to use than the VAS. ${ }^{72,73}$ The NRS has shown evidence of a ceiling effect when used to assess "average" breathlessness severity in people with cancer and non-malignant cardiorespiratory disease. ${ }^{69}$ A pooled analysis reported that no respondent selected a score $>8 / 10$ to describe "average" breathlessness severity despite concurrent ratings of 10 (maximal) on Borg's CR10 scale. ${ }^{69}$ When assessing "average" breathlessness severity (eg, average over the past $24 \mathrm{hrs}$ ), Borg's CR10 scale may therefore be preferable. Few respondents, however, select 0.5 (eg, very, very slight) using Borg's CR10 scale, which may make it unsuitable for assessing low levels of breathlessness. ${ }^{69}$ Cut-offs for categorizing breathlessness severity on a $0-10$ NRS have been reported as none $=0$, mild $=1-4$, moderate $=5-8$, and severe $=9-10 .^{74}$ This can be compared with the non-linear Borg CR10, where a score of 5 is labelled as severe. ${ }^{67}$ 


\section{Assessment of Change}

The responsiveness and estimated MCID of the NRS, VAS, and Borg's CR10 scale are dependent on their context of use and the selected recall focal period, which can vary markedly across studies. For the VAS, the MCID has been estimated at $10 \mathrm{~mm}$ for "current" breathlessness intensity and breathlessness unpleasantness and the average, best and worst breathlessness intensity over the previous 24 hours. $^{75,76}$ The MCID for breathlessness severity "now" or "average over past 24-hrs" assessed with the NRS has been estimated as 1 unit in people with cancer and non-malignant cardiorespiratory disease. ${ }^{76}$ Studies to report a MCID for Borg's CR10 scale most often assess evoked breathlessness, which will be discussed in the Assessment During Exercise section below.

\section{Multidimensional Instruments}

Unidimensional rating scales are also integrated into more comprehensive, multidimensional symptom assessment instruments, such as the Multidimensional Dyspnea Profile (MDP) ${ }^{77}$ and Dyspnoea-12 (D-12). ${ }^{78}$ The MDP comprises 11 items each rated on a $0-10$ NRS. All items assess aspects of breathlessness, including overall unpleasantness, intensity of five sensory qualities (muscle work/effort, air hunger, chest tightness, mental effort, and breathing a lot), and intensity of five emotional responses of breathlessness (depressed, anxious, frustrated, angry, and afraid). ${ }^{77}$ The MDP builds on a framework from pain research and was developed to measure dimensions of breathlessness across populations and settings (laboratory, clinical, daily life). The MDP is not intended for use in its entirety (although it is feasible and relatively quick to use) ${ }^{79}$ but rather as a collection of scales with standardized instructions, wordings and anchors for assessing one or a number of dimensions of breathlessness as needed, to promote consistency and facilitate comparisons between trials. If an MDP summary score is sought, the overall unpleasantness (A1) score is recommended for use. ${ }^{77,80}$ The D-12 has 12 breathlessness descriptors pertaining to the different qualitative dimensions of breathlessness, rated on a $0-4$ Likert scale, where $0=$ "none", $1=$ "mild", $2=$ "moderate" and $3=$ "severe". ${ }^{78}$ All items of the D-12 can be summed for a total score (0-36), or the total score can also be divided into two subdomains - Physical (relating most closely to sensory qualities) and Affective (relating more to emotional responses). ${ }^{78,81-83}$

\section{Assessment of Severity}

Both the MDP and D-12 have been shown to be feasible and quick to use; however, the MDP may be slightly more difficult for respondents to complete compared to the D-12 requiring further explanation on some items. ${ }^{79}$ Most respondents complete the MDP in 5-10 minutes whereas respondents complete the D-12 in $<5$ min. ${ }^{79}$ The MDP has been translated into a range of languages and is validated in the laboratory setting, ${ }^{77}$ and in patients in the emergency department ${ }^{77,85}$ and in outpatients with cardiorespiratory disease ${ }^{80,83,86}$ as well as in elderly people aged $75+$ years. ${ }^{87}$ The D-12 has been validated in COPD as well as a wide range of different heart- and lung diseases. ${ }^{78,81-83}$ The MDP and D-12 have demonstrated similar strength of associations with measures of HRQoL (Hospital Anxiety and Depression Scale, Chronic Respiratory Disease Questionnaire) and the mMRC. ${ }^{83}$ Neither the MDP nor the D-12 directly assess activityrelated breathlessness, and rather, assess breathlessness severity over different recall focal periods. The focal period for the MDP is intended to be defined by the user. ${ }^{77}$ The D-12 developer recommended a focal period of "these days". ${ }^{78,82,84}$

\section{Assessment of Change}

MCIDs for the MDP and D-12 total and subdomain scores have been reported for people with cancer and nonmalignant cardiorespiratory disease, including COPD. ${ }^{79}$ For people with COPD, the MCID for the MDP A1 unpleasantness score has been estimated to be around 1 unit $(0.58,95 \% \mathrm{CI}=0.06,1.10){ }^{79}$ The MDP also permits subscores to be calculated and reported, of which, MCID estimates are 3 units for the Immediate Perception domain and 2 units for the Emotional Response domain. ${ }^{79}$ For the D-12, the MCID in people with COPD has been estimated to be 3 units $(2.68,95 \% \mathrm{CI}=1.16,4.20)$ for the Total score. $^{79}$ MCIDs for the D-12 and MDP were similar between assessment at two weeks and six months, enabling use in both short- and long-term trials. ${ }^{79}$

\section{COPD Symptom Questionnaires}

In addition to breathlessness-specific instruments, there are COPD symptom questionnaires that include individual items on activity-related breathlessness, including but not limited to, the COPD Assessment Test (CAT) ${ }^{88}$ and the Evaluating Respiratory Symptoms in COPD (E-RS) questionnaire. ${ }^{89}$ The CAT contains eight $0-5$ rating scales to assess different COPD symptoms. The breathlessness 
item is anchored by "when I walk up a hill or one flight of stairs, I am not breathless" = 0 to "When I walk up a hill or one flight of stairs, I am very breathless" $=5$. The CAT total score is recommended for reporting, which ranges from 0 to 40 . The E- $R S$ contains 11 items relating to the severity of COPD symptoms in three categories of breathlessness, cough and sputum, and chest-related symptoms (congestion, tightness and discomfort) during different personal care, outdoor and indoor activities. ${ }^{89}$ There are five breathlessness items, which respondents rate on a fivepoint scale to yield a single total score and three subscores for each symptom category. The instrument was designed to be completed in the evening, recalling symptoms "today".

\section{Assessment of Severity}

The CAT was developed and validated to enable a simple evaluation of the symptom impact of COPD. ${ }^{88}$ The complete instrument has demonstrated high internal consistency and good test-retest reliability in people with acute and stable COPD. The CAT total score discriminates between people with acute versus stable COPD and has good convergent validity when compared to other measures of HRQoL. ${ }^{88}$ A CAT total score of $>10$ has previously been defined as equating to "medium impact"; the Global Initiative of Obstructive Lung Disease international guidelines recommend an individual with a CAT score $\geq 10$ be considered as having a high symptom burden. ${ }^{55}$ The breathlessness-specific item, however, has not been validated for stand-alone use. There is some emerging evidence that individual CAT items provide additional information to the CAT total score, such as the ability to predict the presence of undiagnosed COPD or emphysema, however further research is needed in this regard. ${ }^{90,91}$ Both the E- $R S$ total- and E- $R S$ sub-scores have demonstrated good internal consistency and test-retest reliability over two consecutive days. ${ }^{89}$ Moderate associations between the total score and the breathlessness sub-score, and other measures of HRQoL have also been reported in people with COPD. ${ }^{89,92,93}$

\section{Assessment of Change}

The CAT total score has shown to be responsive to change, both in response to therapeutic intervention and worsening health status with COPD acute exacerbation. ${ }^{88,94-98}$ A MCID for the CAT total score has been estimated as 2 units. $^{99}$ A change in CAT total score is, however, not specific to activity-related breathlessness; a meaningful change in CAT total score may be recorded with no change in the breathlessness item, or a worsening in the breathlessness item if other symptom items demonstrated improvement. ${ }^{98}$ In contrast, both the E-RS total score and breathlessness-specific sub-score have demonstrated responsiveness to pharmacological intervention, with the MCIDs estimated to be 2 and 1 units, respectively. ${ }^{92}$

\section{Limitations to Assessment of Breathlessness in Daily Life}

While the aforementioned breathlessness assessment instruments provide important information relating to the breathlessness experienced in daily life by people with COPD, several important limitations need to be considered. Daily life instruments pertain to a recall of the breathlessness experience over a focal period. Importantly, recall (involving cognition and memory) might not reflect the symptom that was actually experienced during the time period or activity. ${ }^{100,101}$ While symptom recall forms the basis for most medical assessment and management, it is influenced by a number of factors including the person's mood and symptom severity at the time of assessment, as well as the peak (worst) symptom level during the recall period, ie, the peak-end-rule. $^{101,102}$

Another important limitation to daily life assessment is the lack of standardization of assessment conditions including of the person's level of physical activity. ${ }^{103,104}$ Breathlessness and exertion are intimately linked, which has several implications: physical activities are likely to vary substantially between individuals (making comparisons of symptom severity difficult between people) as well as for individuals over time (complicating assessment of change and treatment effects). People are likely to reduce their physical activity in the setting of worsening breathlessness to avoid distress from the symptom (which could mask deteriorating symptoms) or increase their activity up to their exertional symptom threshold in response to improvement (which could mask a treatment effect, yielding "false negative" findings for daily life assessments). Change in the underlying physical activity could explain the discrepancy between effects shown in controlled laboratory settings and daily life trials. ${ }^{105}$ Thus, assessment of breathlessness should optimally be performed at a standardized level of exertion. ${ }^{103}$

\section{Assessment During Exercise}

An alternate approach to the assessment of activity-related breathlessness is to assess the breathlessness response to 
different exercise stimuli. Historically, many different exercise tests have been used to evoke breathlessness that are self-paced (eg, six-minute walk test [6MWT]), symptom-limited incremental (INCR) (eg, INCR cardiopulmonary exercise test [CPET], INCR shuttle walk test) or constant work rate (CWR) (eg, CWR CPET, endurance shuttle walk test, stair-stepping and shuttle walking tests).

CWR exercise tests are most suited for the assessment of exertional breathlessness, abiding by the principles of psychophysics. That is, breathlessness is evaluated in response to a standardized exercise stimulus. In contrast, for exercise tests that are self-paced, the person is free to modify their walking pace (exercise intensity), often in accordance with their level of breathlessness. Therefore, while the distance walked may change over time, the level of breathlessness may be the same or unchanged. A similar situation occurs with symptom limited INCR exercise tests. The participant decides the point at which to terminate the test, which may be, at least in part, driven by intolerable breathlessness. Over time, while the exercise intensity at exercise termination may increase with treatment or decrease with disease progression, the level of breathlessness considered intolerable likely stays the same. Importantly, 6MWT and other self-paced or symptom limited INCR tests are valid tests of exercise tolerance or capacity but are not well suited for assessing breathlessness.

A detailed summary of the properties of different exercise tests for breathlessness assessment is beyond the scope of this review and has previously been published. ${ }^{104}$ Briefly, validated CWR exercise tests include the CWR CPET or the 3-min constant-rate stair stepping test (3-min CRSST) and the 3-min constant-speed shuttle test (3-min CSST). The CWR CPET is most often performed in the laboratory on a motorized treadmill or electronically braked cycle ergometer. The participant exercises at a relatively high exercise intensity $(75-80 \%$ of peak power output determined using INCR CPET) ${ }^{109}$ until symptom limitation. Breathlessness is assessed serially throughout testing and at end exercise. The 3-min CRSST $^{110}$ and 3-min CSST $^{110}$ are a lower resource option compared to the CWR CPET, simple equipment is required, and no prior INCR exercise test is required to be completed. ${ }^{104}$ For the 3-min CRSST, the participant steps up and down a 20-cm step for 3-min to the pace of an automated audio beep. The test ends at 3-min, or at symptom limitation. The 3-min CSST follows the same protocol, except that rather than stepping, the participant walks back and forth between two marker cones set 9 meters apart. Breathlessness is assessed at 1-min intervals throughout testing and at end exercise.

The choice of which exercise test to use for assessment of exertional breathlessness depends on the preferred mode and available resources and expertise. The following sections will present a summary of different instruments that can be used for breathlessness assessment during various exercise test modes.

\section{Unidimensional Rating Scales Assessment of Severity}

Borg's CR10 scale is the most widely used instrument to assess the intensity of breathlessness during exercise in people with COPD; its non-linear scaling properties were designed for consideration of the non-linear physiological and perceptual responses to exercise. ${ }^{67,68}$ When assessing breathlessness during exercise in COPD, respondents are most commonly asked to "rate the intensity of their breathing discomfort", capturing the overall intensity of the sensation. ${ }^{1}$

Breathlessness intensity in response to exercise provocation is best assessed at a standardized submaximal timepoint (isotime), power output, rate of oxygen consumption $\left(\mathrm{V}^{\prime} \mathrm{O}_{2}\right)$ or minute ventilation $\left(\mathrm{V}_{\mathrm{E}}^{\prime}\right)$ during $\mathrm{CWR}$ or INCR CPET. ${ }^{111-114}$ Assessment of breathlessness intensity at isotime during high-intensity ( $75 \%$ peak power output) CWR CPET $^{115}$ or INCR cycle CPET $^{116}$ using Borg's CR10 scale has shown high test-retest reliability in people with COPD. Conversely, it is well established that Borg CR10 scale intensity ratings of breathlessness at the symptom limited peak of CPET do not discriminate between people with versus without $\mathrm{COPD}^{111-113}$ or people with mild, moderate, severe and very severe COPD. ${ }^{111,114}$ This is due to reasons previously mentioned; people often stop exercising at similar levels of breathlessness intensity despite exercising for longer or to higher peak power outputs, $\mathrm{V}^{\prime} \mathrm{O}_{2}$ or $\mathrm{V}^{\prime}{ }_{\mathrm{E}}$ (eg, refer to Figure 5 of $^{114}$ ).

\section{Assessment of Change}

As with assessment of breathlessness severity, Borg CR10 scale intensity ratings of breathlessness at the symptom limited peak of CPET are not helpful in evaluating a change in breathlessness in response to therapeutic intervention. ${ }^{117-122}$ Borg CR10 scale intensity ratings of breathlessness at isotime during CWR cycle CPET have, however, been shown to be responsive to both 
pharmacologic and non-pharmacologic interventions in people with COPD. ${ }^{117-122}$

Using a distribution-based approach based primarily on effect size, Ries ${ }^{106}$ recommended two different MCIDs for breathlessness intensity ratings at isotime during exercise: 1) MCID of 2 Borg CR10 scale units for "stronger" interventions with large effect sizes above 0.8 , such as rehabilitative exercise training or lung volume reduction surgery in emphysema; or 2) MCID of 1 Borg CR10 scale unit for less intensive interventions with more moderate effects sizes, such as supplemental oxygen or bronchodilator therapy. Based on the results of Ries' report, ${ }^{106}$ Cazzola et $\mathrm{al}^{107}$ and Jones et $\mathrm{al}^{108}$ recommended a MCID of 2 and 1 units on the Borg CR10 scale, respectively, for breathlessness intensity during exercise. These estimates were specific to change in breathlessness intensity with pharmacological intervention in people with COPD. ${ }^{107,108}$ In most cases, we believe that a MCID of 1 Borg CR10 scale unit is appropriate to evaluate the effect of a therapeutic intervention on exertional breathlessness in people with COPD.

\section{Multidimensional Instruments Assessment of Severity}

As previously discussed, the MDP and D-12 assess the multiple dimensions of breathlessness, as recommended by the American Thoracic Society. ${ }^{1}$ These instruments were, however, designed for recalling breathlessness sensations at rest, and because of the time they take to complete (5-10 min each), they are impractical for use during exercise, regardless of COPD status or severity. These tools may be appropriate for the assessment of breathlessness at exercise cessation, the MDP has been shown to be reliable in this context. ${ }^{123}$

For breathlessness assessment during exercise, two recent studies - albeit in healthy younger adults - provide evidence for use of serial Borg CR10 scales to assess increases in breathlessness intensity and unpleasantness $^{123,124}$ as well as common breathlessness sensory qualities, unsatisfied inspiration and work/effort of breathing. ${ }^{124}$ In people with COPD, a single recent study similarly obtained serial Borg CR10 scale ratings of multiple breathlessness dimensions during INCR cycle CPET, including ratings of overall breathlessness intensity, unsatisfied inspiration, breathing too shallow, work/effort of breathing, and breathlessness-related unpleasantness, fear and anxiety. ${ }^{112}$ People with COPD separately rated the intensity and unpleasantness of breathlessness during exercise, and reported moderate levels of breathlessnessrelated fear and anxiety toward end exercise. ${ }^{112}$ The findings of this study suggested that important information on the breathlessness response to exercise can be obtained by assessing multiple dimensions of the sensation.

\section{Assessment of Change}

While there is some evidence to support the use of Borg's CR10 scale to assess the severity of the multiple dimensions of breathlessness during exercise in people with COPD (and to discriminate between people with versus without COPD), it remains unclear whether the multiple dimensions of exertional breathlessness assessed in this way would be responsive to change following therapeutic intervention(s), or as a consequence of disease progression/worsening health status in people with COPD. There is also no MCID for the change in Borg CR10 scale ratings of the sensory quality and affective (unpleasantness, fear, anxiety) dimensions of exertional breathlessness in COPD. Further research is required to address these knowledge gaps before evidence-based recommendations can be made around multidimensional assessment of exertional breathlessness in people with COPD.

\section{Limitations to Assessment During Exercise}

Assessment of breathlessness in response to an acute exercise stimulus provides a direct measurement of exertional breathlessness not prone to recall bias; however, there are other potential limitations to be considered. The exercise conditions in which breathlessness is assessed do not directly reflect real-life. A single exercise mode is often performed (stair-stepping, walking, cycling), which may exclude some of the most problematic daily life activities for people with COPD. ${ }^{13}$ Further, testing is performed in a highly controlled hospital or laboratory environment, supervised by an exercise or medical professional. These factors may limit the generalizability to breathlessness that would be experienced under less controlled, real-life conditions.

Another important consideration is the lack of data around what constitutes a normal level of breathlessness for any given exercise stimuli. Provision of normative data from healthy age- and sex-matched adults would facilitate a more meaningful interpretation of exertional breathlessness responses observed in people with COPD. Evidence is emerging around normative reference sets, including a recent study reporting normative breathlessness responses assessed with Borg's CR10 scale during cycle 
exercise testing. ${ }^{125}$ Normative ranges for breathlessness at any given absolute power output or $\mathrm{V}_{\mathrm{E}}^{\prime}$ were reported according to participant sex and age group. ${ }^{125}$ Further research is needed to extend on these initial reports and include normative breathlessness responses across different exercise modalities and in relation to other commonly measured physiological measures such as $\mathrm{V}^{\prime} \mathrm{O}_{2}$.

Text Box I Proposed Instruments to Assess Activity-Related Breathlessness in People with COPD

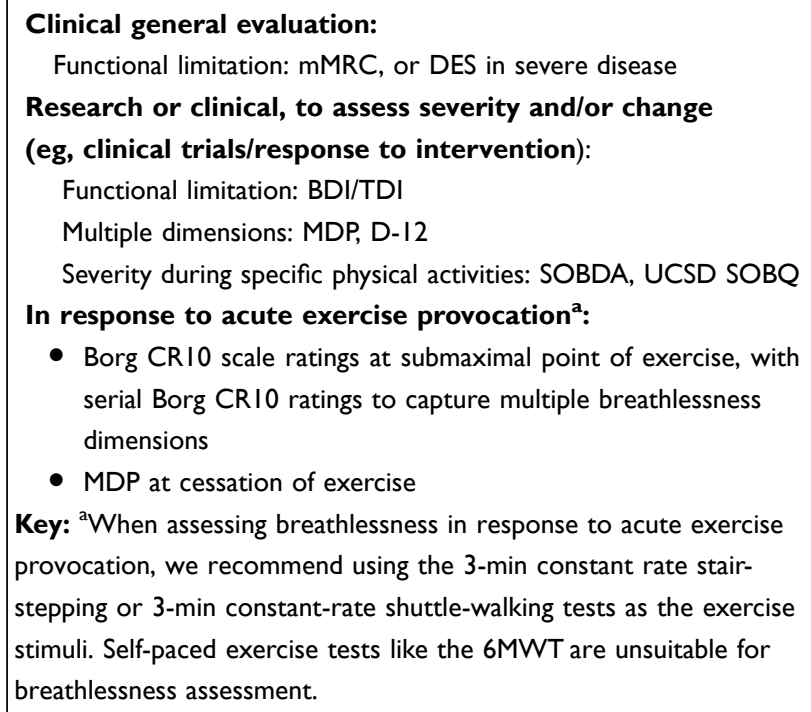

\section{Proposed Instruments to Use}

Provided in Text Box 1 are proposed instruments to be used in the clinical or research setting for assessment of breathlessness. The specific instrument selected for use will depend on the purpose of assessment and what the assessor aims to achieve or understand by completing the assessment.

\section{Conclusion: Gaps and Future Needs}

There have been extensive developments in the field of breathlessness assessment over the last 30 years, with a multitude of assessment instruments now available to capture information on the breathlessness experience of people with COPD in different settings and contexts. A number of previous reviews have provided a summary of available breathlessness assessment approaches in these varied contexts, including instruments to assess breathlessness at specific times of the day (ie, morning symptoms), ${ }^{126}$ to capture the multiple dimensions of breathlessness ${ }^{127}$ and specific to people with advanced disease. ${ }^{49}$ The current review focuses on the assessment of activity-related breathlessness experienced in daily life or in response to an exercise provocation.
The importance of assessing activity-related breathlessness for people with COPD is highlighted by international clinical practice guidelines and drug regulatory agencies (eg, Food and Drug Administration of America), which suggest assessment of activity-related breathlessness is integral for clinical decision-making and evaluation of treatment efficacy. ${ }^{128}$ While much progress has been made, there are important areas in need of further research. Trials are warranted on the responsiveness of instruments to different (non-pharmacological) interventions, and over longer periods of time. ${ }^{128}$ In regard to assessment of breathlessness in response to exercise provocation, further studies are needed to support the proposed MCID of 1 Borg CR10 scale unit assessed at a standardized submaximal time point during CPET. These studies could also be extended to include evaluation of the responsiveness and MCID of the Borg CR10 scale for assessing the multiple dimensions of breathlessness during exercise. Further, the "normal" predicted breathlessness response to exercise needs to be established so clinicians and researchers can determine whether an individual has "out of proportion" breathlessness and potentially unmask breathlessness that remains unreported and "hidden". Normative data will provide the first standardized approaches to compare breathlessness severity between people.

The documented language around breathlessness has been derived predominantly from English centric perspectives, and existing breathlessness assessment approaches developed based on English descriptors of breathlessness. To overcome linguistic and cultural differences, English breathlessness assessment instruments have been translated to various languages, most commonly via the forward-backward translation method. While this provides an option for breathlessness assessment in non-English speakers, it limits the language used for translations of English phrases, which may not be reflective of the breathlessness experienced by non-English-speaking people. Further research is needed to better understand how linguistically and culturally diverse people experience breathlessness, to optimize breathlessness assessment in these populations.

\section{Disclosure}

HL has no conflicts to disclose. ME was supported by unrestricted grants from the Swedish Society for Medical Research and the Swedish Research Council (Dnr 201902081). DJ holds a Canada Research Chair in Clinical 
Exercise and Respiratory Physiology (Tier 2) from the Canadian Institutes of Health Research. The authors report no other conflicts of interest in this work.

\section{References}

1. Parshall MB, Schwartzstein RM, Adams L, et al. An Official American Thoracic Society Statement: update on the mechanisms, assessment, and management of dyspnea. Am J Respir Crit Care Med. 2012;185(4):435-452. doi:10.1164/rccm.2011112042ST

2. Bowden JA, To TH, Abernethy AP, Currow DC. Predictors of chronic breathlessness: a large population study. BMC Public Health. 2011;11:33. doi:10.1186/1471-2458-11-33

3. Currow DC, Plummer JL, Crockett A, Abernethy AP. A community population survey of prevalence and severity of dyspnea in adults. J Pain Symptom Manage. 2009;38(4):533-545. doi:10.1016/j.jpainsymman.2009.01.006

4. Sandberg J, Ekström M, Börjesson M, et al. Underlying contributing conditions to breathlessness among middle-aged individuals in the general population: a cross-sectional study. $B M J$ Open Respir Res. 2020;7(1):e000643. doi:10.1136/bmjresp2020-000643

5. Jensen D, Ofir D, O'Donnell DE. Effects of pregnancy, obesity and aging on the intensity of perceived breathlessness during exercise in healthy humans. Respir Physiol Neurobiol. 2009;167 (1):87-100. doi:10.1016/j.resp.2009.01.011

6. Solano JP, Gomes B, Higginson IJ. A comparison of symptom prevalence in far advanced cancer, AIDS, heart disease, chronic obstructive pulmonary disease and renal disease. J Pain Symptom Manage. 2006;31(1):58-69. doi:10.1016/j.jpainsymma n.2005.06.007

7. Johnson MJ, Bowden JA, Abernethy AP, Currow DC. To what causes do people attribute their chronic breathlessness? A population survey. $J$ Palliat Med. 2012;15(7):744-750. doi:10.1089/jpm.2011.0430

8. Hutchinson A, Pickering A, Williams P, Bland JM, Johnson MJ. Breathlessness and presentation to the emergency department: a survey and clinical record review. BMC Pulm Med. 2017;17 (1):53. doi:10.1186/s12890-017-0396-4

9. Carette H, Zysman M, Morelot-Panzini C, et al. Prevalence and management of chronic breathlessness in COPD in a tertiary care center. BMC Pulm Med. 2019;19(1):95. doi:10.1186/s12890-0190851-5

10. Mullerova H, Lu C, Li H, Tabberer M. Prevalence and burden of breathlessness in patients with chronic obstructive pulmonary disease managed in primary care. PLoS One. 2014;9(1):e85540. doi:10.1371/journal.pone.0085540

11. Miravitlles M, Ribera A. Understanding the impact of symptoms on the burden of COPD. Respir Res. 2017;18(1):67. doi:10.1186/ s12931-017-0548-3

12. Lewthwaite H, Effing TW, Lenferink A, Olds T, Williams MT. Improving physical activity, sedentary behaviour and sleep in COPD: perspectives of people with COPD and experts via a Delphi approach. PeerJ. 2018;6:e4604. doi:10.7717/peerj.4604

13. Michalovic E, Jensen D, Dandurand RJ, et al. Description of participation in daily and social activities for individuals with COPD. COPD. 2020;17(5):1-14. doi:10.1080/ 15412555.2020.1798373

14. Currow DC, Dal Grande E, Ferreira D, Johnson MJ, McCaffrey N, Ekström M. Chronic breathlessness associated with poorer physical and mental health-related quality of life (SF-12) across all adult age groups. Thorax. 2017;72 (12):1151-1153. doi:10.1136/thoraxjnl-2016-209908
15. Smith AK, Currow DC, Abernethy AP, et al. Prevalence and outcomes of breathlessness in older adults: a National Population Study. J Am Geriatr Soc. 2016;64(10):2035-2041. doi:10.1111/jgs. 14313

16. Sandberg J, Engstrom G, Ekstrom M. Breathlessness and incidence of COPD, cardiac events and all-cause mortality: a 44-year follow-up from middle age throughout life. PLoS One. 2019;14 (3):e0214083. doi:10.1371/journal.pone.0214083

17. Frostad A, Soyseth V, Haldorsen T, Andersen A, Gulsvik A. Respiratory symptoms and 30 year mortality from obstructive lung disease and pneumonia. Thorax. 2006;61(11):951-956. doi: $10.1136 /$ thx.2006.059436

18. Sundh J, Ekstrom M. Persistent disabling breathlessness in chronic obstructive pulmonary disease. Int J Chron Obstruct Pulmon Dis. 2016;11:2805-2812. doi:10.2147/COPD.S119992

19. Johnson MJ, Yorke J, Hansen-Flaschen J, et al. Towards an expert consensus to delineate a clinical syndrome of chronic breathlessness. Eur Respir J. 2017;49(5):1602277. doi:10.1183/ 13993003.02277-2016

20. Hutchinson A, Johnson MJ, Currow D. Acute-on-chronic breathlessness: recognition and response. J Pain Symptom Manage. 2019;57(5):e4-e5. doi:10.1016/j.jpainsymman.2019.01.012

21. Hutchinson A, Galvin K, Johnson MJ. "So, I try not to go ..." acute-on-chronic breathlessness and presentation to the emergency department: in-depth interviews with patients, carers, and clinicians. J Pain Symptom Manage. 2020;60(2):316-325. doi:10.1016/j.jpainsymman.2020.03.014

22. Jolley CJ, Luo YM, Steier J, Rafferty GF, Polkey MI, Moxham J. Neural respiratory drive and breathlessness in COPD. Eur Respir J. 2015;45(2):355-364. doi:10.1183/09031936.00063014

23. Jolley CJ, Moxham J. A physiological model of patient-reported breathlessness during daily activities in COPD. Eur Respir $J$. 2009;18(112):66-79. doi:10.1183/09059180.00000809

24. O’Donnell DE, Milne KM, James MD, de Torres JP, Neder JA. Dyspnea in COPD: new mechanistic insights and management implications. Adv Ther. 2020;37(1):41-60. doi:10.1007/s12325019-01128-9

25. Faull OK, Marlow L, Finnegan SL, Pattinson KTS. Chronic breathlessness: re-thinking the symptom. Eur Respir J. 2018;51 (1):1702238. doi:10.1183/13993003.02238-2017

26. Marlow LL, Faull OK, Finnegan SL, Pattinson KTS. Breathlessness and the brain: the role of expectation. Curr Opin Support Palliat Care. 2019;13(3):200-210. doi:10.1097/ SPC.0000000000000441

27. Bailey PH. The dyspnea-anxiety-dyspnea cycle-COPD patients' stories of breathlessness: "It's scary/when you can't breathe". Qual Health Res. 2004;14(6):760-778. doi:10.1177/ 1049732304265973

28. Eltayara L, Becklake MR, Volta CA, Milic-Emili J. Relationship between chronic dyspnea and expiratory flow limitation in patients with chronic obstructive pulmonary disease. Am J Respir Crit Care Med. 1996;154(6):1726-1734. doi:10.1164/ ajrccm.154.6.8970362

29. Mahler DA, Weinberg DH, Wells CK, Feinstein AR. The measurement of dyspnea. Contents, interobserver agreement, and physiologic correlates of two new clinical indexes. Chest. 1984;85(6):751-758. doi:10.1378/chest.85.6.751

30. Santos LM, Pedro PI, Dias A, Forte CB, Raposo P, Rodrigues MF. Relationship between dyspnea/oxygen saturation and leg discomfort/6-minute walking distance in patients with COPD participating in pulmonary rehabilitation. Pulmonology. 2019;25(6):357-360. doi:10.1016/j.pulmoe.2019.07.012

31. Banzett RB, Pedersen SH, Schwartzstein RM, Lansing RW. The affective dimension of laboratory dyspnea: air hunger is more unpleasant than work/effort. Am J Respir Crit Care Med. 2008;177(12):1384-1390. doi:10.1164/rccm.200711-1675OC 
32. Herigstad M, Faull OK, Hayen A, et al. Treating breathlessness via the brain: changes in brain activity over a course of pulmonary rehabilitation. Eur Respir J. 2017;50(3):1701029. doi:10.1183/13993003.01029-2017

33. Ahmadi Z, Sandberg J, Shannon-Honson A, Vandersman Z, Currow DC, Ekström M. Is chronic breathlessness less recognised and treated compared with chronic pain? A case-based randomised controlled trial. Eur Respir J. 2018;52(3):1800887. doi:10.1183/13993003.00887-2018

34. Gysels M, Higginson IJ. Access to services for patients with chronic obstructive pulmonary disease: the invisibility of breathlessness. J Pain Symptom Manage. 2008;36(5):451-460. doi:10.1016/j.jpainsymman.2007.11.008

35. Lunn S, Dharmagunawardena R, Lander M, Sweeney J. It's hard to talk about breathlessness: a unique insight from respiratory trainees. Clin Med. 2019;19(4):344-347. doi:10.7861/clinmedicine. 19-4-344

36. Jaeschke R, Singer J, Guyatt GH. Measurement of health status. Ascertaining the minimal clinically important difference. Control Clin Trials. 1989;10(4):407-415. doi:10.1016/0197-2456(89) 90005-6

37. Guyatt GH, Osoba D, Wu AW, Wyrwich KW, Norman GR; Clinical Significance Consensus Meeting G. Methods to explain the clinical significance of health status measures. Mayo Clin Proc. 2002;77(4):371-383. doi:10.4065/77.4.371

38. Norman GR, Sloan JA, Wyrwich KW. Interpretation of changes in health-related quality of life: the remarkable universality of half a standard deviation. Med Care. 2003;41(5):582-592. doi:10.1097/01.MLR.0000062554.74615.4C

39. Mahler DA, Wells CK. Evaluation of clinical methods for rating dyspnea. Chest. 1988;93(3):580-586. doi:10.1378/chest.93.3.580

40. Brookes SM. Task group on surveillance for respiratory hazards in the occupational setting. ATS News. 1982;8:12-16

41. Fletcher C. Standardised questionnaire on respiratory symptoms: a statement prepared and approved by the MRC Committee on the Aetiology of Chronic Bronchitis (MRC breathlessness score). BMJ. 1960;2(2):1665.

42. Sandberg J, Johnson MJ, Currow DC, Ekstrom M. Validation of the dyspnea exertion scale of breathlessness in people with life-limiting illness. $J$ Pain Symptom Manage. 2018;56 (3):430-435. doi:10.1016/j.jpainsymman.2018.05.002

43. McGavin CR, Artvinli M, Naoe H, McHardy GJ. Dyspnoea, disability, and distance walked: comparison of estimates of exercise performance in respiratory disease. $\mathrm{Br}$ Med J. 1978;2 (6132):241-243. doi:10.1136/bmj.2.6132.241

44. Aguilaniu B, Gonzalez-Bermejo J, Regnault A, et al. Disability related to COPD tool (DIRECT): towards an assessment of COPD-related disability in routine practice. Int $J$ Chron Obstruct Pulmon Dis. 2011;6:387-398. doi:10.2147/COPD. S20007

45. Eakin EG, Sassi-Dambron DE, Ries AL, Kaplan RM. Reliability and validity of dyspnea measures in patients with obstructive lung disease. Int J Behav Med. 1995;2(2):118-134. doi:10.1207/ s15327558ijbm0202_3

46. Chhabra SK, Gupta AK, Khuma MZ. Evaluation of three scales of dyspnea in chronic obstructive pulmonary disease. Ann Thorac Med. 2009;4(3):128-132. doi:10.4103/1817-1737.53351

47. Bestall JC, Paul EA, Garrod R, Garnham R, Jones PW, Wedzicha JA. Usefulness of the Medical Research Council (MRC) dyspnoea scale as a measure of disability in patients with chronic obstructive pulmonary disease. Thorax. 1999;54 (7):581-586. doi:10.1136/thx.54.7.581

48. Mahler DA, Ward J, Waterman LA, McCusker C, Zuwallack R, Baird JC. Patient-reported dyspnea in COPD reliability and association with stage of disease. Chest. 2009;136(6):1473-1479. doi:10.1378/chest.09-0934
49. Bausewein C, Farquhar M, Booth S, Gysels M, Higginson IJ. Measurement of breathlessness in advanced disease: a systematic review. Respir Med. 2007;101(3):399-410. doi:10.1016/j. rmed.2006.07.003

50. Dela Coleta K, Silveira LVA, Lima DF, Rampinelli EA, Godoy I, Godoy I. Predictors of first-year survival in patients with advanced COPD treated using long-term oxygen therapy. Respir Med. 2008;102(4):512-518. doi:10.1016/j.rmed.2007.12.003

51. Oga T, Nishimura K, Tsukino M, Hajiro T, Mishima M. Dyspnoea with activities of daily living versus peak dyspnoea during exercise in male patients with COPD. Respir Med. 2006;100 (6):965-971. doi:10.1016/j.rmed.2005.10.006

52. Sundh J, Janson C, Lisspers K, Stallberg B, Montgomery S. The Dyspnoea, Obstruction, Smoking, Exacerbation (DOSE) index is predictive of mortality in COPD. Prim Care Respir J. 2012;21 (3):295-301. doi:10.4104/pcrj.2012.00054

53. Nishimura K, Izumi T, Tsukino M, Oga T. Dyspnea is a better predictor of 5-year survival than airway obstruction in patients with COPD. Chest. 2002;121(5):1434-1440. doi:10.1378/ chest.121.5.1434

54. Casanova C, Marin JM, Martinez-Gonzalez C, et al. Differential Effect of Modified Medical Research Council Dyspnea, COPD assessment test, and clinical COPD questionnaire for symptoms evaluation within the new GOLD staging and mortality in COPD. Chest. 2015;148(1):159-168. doi:10.1378/chest.14-2449

55. From the global strategy for the diagnosis, management and prevention of COPD, global initiative for chronic obstructive lung disease (GOLD); 2021. Available from: http://goldcopd. org. Accessed May 13, 2021.

56. Hajiro T, Nishimura K, Tsukino M, Ikeda A, Koyama H, Izumi T. Analysis of clinical methods used to evaluate dyspnea in patients with chronic obstructive pulmonary disease. Am J Respir Crit Care Med. 1998;158(4):1185-1189. doi:10.1164/ajrccm.158.4.9802091

57. Mahler DA, Ward J, Waterman LA, Baird JC. Longitudinal changes in patient-reported dyspnea in patients with COPD. COPD. 2012;9(5):522-527. doi:10.3109/15412555.2012.701678

58. Guyatt G. Measuring health status in chronic airflow limitation Eur Respir J. 1988;1(6):560-564.

59. Witek TJ Jr, Mahler DA. Meaningful effect size and patterns of response of the transition dyspnea index. J Clin Epidemiol. 2003;56(3):248-255. doi:10.1016/S0895-4356(02)00589-9

60. Mahler DA, Witek TJ Jr. The MCID of the transition dyspnea index is a total score of one unit. Chronic Obstr Pulm Dis. 2005;2 (1):99-103. doi:10.1081/COPD-200050666

61. Levesque J, Antoniadis A, Li PZ, et al. Minimal clinically important difference of 3-minute chair rise test and the DIRECT questionnaire after pulmonary rehabilitation in COPD patients. Int $J$ Chron Obstruct Pulmon Dis. 2019;14:261-269. doi:10.2147/COPD.S187567

62. Watkins ML, Wilcox TK, Tabberer M, et al. Shortness of breath with daily activities questionnaire: validation and responder thresholds in patients with chronic obstructive pulmonary disease. BMJ Open. 2013;3(10):e003048. doi:10.1136/bmjopen2013-003048

63. Howard K, Berry P, Petrillo J, et al. Development of the shortness of breath with daily activities questionnaire (SOBDA). Value Health. 2012;15(8):1042-1050. doi:10.1016/j.jval.2012.06.018

64. Eakin EG, Resnikoff PM, Prewitt LM, Ries AL, Kaplan RM. Validation of a new dyspnea measure: the UCSD shortness of breath questionnaire. University of California, San Diego. Chest. 1998;113(3):619-624. doi:10.1378/chest.113.3.619

65. Wilcox TK, Chen W-H, Howard KA, et al. Item selection, reliability and validity of the shortness of breath with daily activities (SOBDA) questionnaire: a new outcome measure for evaluating dyspnea in chronic obstructive pulmonary disease. Health Qual Life Outcomes. 2013;11(1):196. doi:10.1186/1477-7525-11-196 
66. Horita N, Miyazawa N, Morita S, et al. Small, moderate, and large changes, and the minimum clinically important difference in the University of California, San Diego shortness of breath questionnaire. COPD. 2014;11(1):26-32. doi:10.3109/ 15412555.2013.808615

67. Borg G. Psychophysical bases of perceived exertion. J Med Sci Sports Exerc. 1982;14(5):377-381.

68. Borg G A category scale with ratio properties for intermodal and interindividual comparisons. In: Geissler HG, Petzol P, editors. Psychophysical Judgement and the Process of Perception. Proceedings of the 22nd International Congress of Psychology. Amsterdam, The Netherlands: North Holland Publishing Co; 1980:25-34.

69. Johnson MJ, Close L, Gillon SC, Molassiotis A, Lee PH, Farquhar MC. Use of the modified Borg scale and numerical rating scale to measure chronic breathlessness: a pooled data analysis. Eur Respir J. 2016;47(6):1861-1864. doi:10.1183/ 13993003.02089-2015

70. Burdon JG, Juniper EF, Killian KJ, Hargreave FE, Campbell EJ. The perception of breathlessness in asthma. Am Rev Respir Dis. 1982;126(5):825-828. doi:10.1164/arrd.1982.126.5.825

71. Kendrick KR, Baxi SC, Smith RM. Usefulness of the modified 0-10 Borg scale in assessing the degree of dyspnea in patients with COPD and asthma. J Emerg Nurs. 2000;26(3):216-222. doi:10.1016/S0099-1767(00)90093-X

72. Wilcock A, Crosby V, Clarke D, Tattersfield A. Repeatability of breathlessness measurements in cancer patients. Thorax. 1999;54 (4):374. doi:10.1136/thx.54.4.374b

73. Gift AG, Narsavage G. Validity of the numeric rating scale as a measure of dyspnea. Am J Crit Care. 1998;7(3):200-204. doi:10.4037/ajcc1998.7.3.200

74. Wysham NG, Miriovsky BJ, Currow DC, et al. Practical dyspnea assessment: relationship between the 0-10 numerical rating scale and the four-level categorical verbal descriptor scale of dyspnea intensity. $J$ Pain Symptom Manage. 2015;50(4):480-487. doi:10.1016/j.jpainsymman.2015.04.015

75. Ekström M, Johnson MJ, Huang C, Currow DC. Minimal clinically important differences in average, best, worst and current intensity and unpleasantness of chronic breathlessness. Eur Respir J. 2020;56(2):1902202. doi:10.1183/13993003.022022019

76. Johnson MJ, Bland JM, Oxberry SG, Abernethy AP, Currow DC. Clinically important differences in the intensity of chronic refractory breathlessness. J Pain Symptom Manage. 2013;46 (6):957-963. doi:10.1016/j.jpainsymman.2013.01.011

77. Banzett RB, O'Donnell CR, Guilfoyle TE, et al. Multidimensional dyspnea profile: an instrument for clinical and laboratory research. Eur Respir J. 2015;45(6):1681-1691. doi:10.1183/09031936.00038914

78. Yorke J, Moosavi SH, Shuldham C, Jones PW. Quantification of dyspnoea using descriptors: development and initial testing of the dyspnoea-12. Thorax. 2010;65(1):21-26. doi:10.1136/ thx.2009.118521

79. Ekström MP, Bornefalk H, Sköld CM, et al. Minimal clinically important differences and feasibility of dyspnea-12 and the multidimensional dyspnea profile in cardiorespiratory disease. J Pain Symptom Manage. 2020;60(5):968-975. doi:10.1016/j. jpainsymman.2020.05.028

80. Ekström M, Bornefalk H, Sköld M, et al. Validation of the Swedish multidimensional dyspnea profile (MDP) in outpatients with cardiorespiratory disease. BMJ Open Respir Res. 2019;6(1): e000381. doi:10.1136/bmjresp-2018-000381

81. Tan J-Y, Yorke J, Harle A, et al. Assessment of breathlessness in lung cancer: psychometric properties of the dyspnea-12 questionnaire. J Pain Symptom Manage. 2017;53(2):208-215. doi:10.1016/j.jpainsymman.2016.08.009
82. Yorke J, Swigris J, Russell AM, et al. Dyspnea-12 is a valid and reliable measure of breathlessness in patients with interstitial lung disease. Chest. 2011;139(1):159-164. doi:10.1378/chest.10-0693

83. Williams MT, John D, Frith P. Comparison of the dyspnoea-12 and multidimensional dyspnoea profile in people with COPD. Eur Respir J. 2017;49(3):1600773. doi:10.1183/13993003.00773-2016

84. Yorke J, Armstrong I. The assessment of breathlessness in pulmonary arterial hypertension: reliability and validity of the dyspnoea-12. Eur J Cardiovasc Nurs. 2014;13(6):506-514. doi:10.1177/1474515113514891

85. Meek PM, Banzett R, Parshall MB, Gracely RH, Schwartzstein RM, Lansing R. Reliability and validity of the multidimensional dyspnea profile. Chest. 2012;141 (6):1546-1553. doi:10.1378/chest.11-1087

86. Morelot-Panzini C, Gilet H, Aguilaniu B, et al. Real-life assessment of the multidimensional nature of dyspnoea in COPD outpatients. Eur Respir J. 2016;47(6):1668-1679. doi:10.1183/ 13993003.01998-2015

87. Hegendörfer E, Doukhopelnikoff A, Degryse J-M. Validity and reliability of the multidimensional dyspnoea profile in older adults. ERJ Open Res. 2020:00606-02020.

88. Jones PW, Harding G, Berry P, Wiklund I, Chen WH, Kline Leidy N. Development and first validation of the COPD assessment test. Eur Respir J. 2009;34(3):648-654. doi:10.1183/ 09031936.00102509

89. Leidy NK, Sexton CC, Jones PW, et al. Measuring respiratory symptoms in clinical trials of COPD: reliability and validity of a daily diary. Thorax. 2014;69(5):443-449. doi:10.1136/thoraxjnl2013-204428

90. Raghavan N, Lam YM, Webb KA, et al. Components of the COPD assessment test (CAT) associated with a diagnosis of COPD in a random population sample. COPD. 2012;9 (2):175-183. doi:10.3109/15412555.2011.650802

91. Marietta von Siemens S, Alter P, Lutter JI, et al. CAT score single item analysis in patients with COPD: results from COSYCONET. Respir Med. 2019;159:105810. doi:10.1016/j.rmed.2019.105810

92. Leidy NK, Murray LT, Monz BU, et al. Measuring respiratory symptoms of COPD: performance of the EXACT- Respiratory Symptoms Tool (E-RS) in three clinical trials. Respir Res. 2014;15(1):124. doi:10.1186/s12931-014-0124-Z

93. Nelsen LM, Lee LA, Wu W, et al. Reliability, validity and responsiveness of E-RS:COPD in patients with spirometric asthma-COPD overlap. Respir Res. 2019;20(1):107. doi:10.1186/s12931-019-1070-6

94. Jones PW, Harding G, Wiklund I, et al. Tests of the responsiveness of the COPD assessment test following acute exacerbation and pulmonary rehabilitation. Chest. 2012;142(1):134-140. doi:10.1378/chest.11-0309

95. Miravitlles M, Garcia-Sidro P, Fernandez-Nistal A, Buendia MJ, Espinosa de Los Monteros MJ, Molina J. Course of COPD assessment test (CAT) and clinical COPD questionnaire (CCQ) scores during recovery from exacerbations of chronic obstructive pulmonary disease. Health Qual Life Outcomes. 2013;11:147. doi:10.1186/1477-7525-11-147

96. Dodd JW, Hogg L, Nolan J, et al. The COPD assessment test (CAT): response to pulmonary rehabilitation. A multicentre, prospective study. Thorax. 2011;66(5):425-429. doi:10.1136/ thx.2010.156372

97. Dodd JW, Marns PL, Clark AL, et al. The COPD assessment test (CAT): short- and medium-term response to pulmonary rehabilitation. COPD. 2012;9(4):390-394. doi:10.3109/15412555.2012.671869

98. Houben-Wilke S, Janssen DJA, Franssen FME, Vanfleteren L, Wouters EFM, Spruit MA. Contribution of individual COPD assessment test (CAT) items to CAT total score and effects of pulmonary rehabilitation on CAT scores. Health Qual Life Outcomes. 2018;16(1):205. doi:10.1186/s12955-018-1034-4 
99. Kon SS, Canavan JL, Jones SE, et al. Minimum clinically important difference for the COPD assessment test: a prospective analysis. Lancet Respir Med. 2014;2(3):195-203. doi:10.1016/ S2213-2600(14)70001-3

100. Sandberg J, Ekström M. Differences between experienced and recalled breathlessness: a review. Curr Opin Support Palliat Care. 2019;13(3):161-166. doi:10.1097/SPC.0000000000000448

101. Meek PM, Lareau SC, Anderson D. Memory for symptoms in COPD patients: how accurate are their reports? Eur Respir J. 2001;18(3):474-481. doi:10.1183/09031936.01.00083501

102. Elmberg V, Ekstrom M. Effect of the trajectory of exertional breathlessness on symptom recall and anticipation: a randomized controlled trial. PLoS One. 2020;15(9):e0238937. doi:10.1371/journal.pone.0238937

103. Ekström M, Elmberg V, Lindow T, Wollmer P. Breathlessness measurement should be standardised for the level of exertion. Eur Respir J. 2018;51(5):1800486. doi:10.1183/13993003.004862018

104. Lewthwaite H, Koch EM, Tracey L, Jensen D. Standardized measurement of breathlessness during exercise. Curr Opin Support Palliat Care. 2019;13(3):152-160. doi:10.1097/ SPC.0000000000000443

105. Ekström M. Why treatment efficacy on breathlessness in laboratory but not daily life trials? The importance of standardized exertion. Curr Opin Support Palliat Care. 2019;13(3):179-183. doi:10.1097/SPC.0000000000000444

106. Ries AL. Minimally clinically important difference for the UCSD shortness of breath questionnaire, Borg Scale, and Visual Analog Scale. COPD. 2005;2(1):105-110. doi:10.1081/COPD200050655

107. Cazzola M, MacNee W, Martinez FJ, et al. Outcomes for COPD pharmacological trials: from lung function to biomarkers. Eur Respir J. 2008;31(2):416-469. doi:10.1183/09031936.00099306

108. Jones PW, Beeh KM, Chapman KR, Decramer M, Mahler DA, Wedzicha JA. Minimal clinically important differences in pharmacological trials. Am J Respir Crit Care Med. 2014;189 (3):250-255. doi:10.1164/rccm.201310-1863PP

109. Palange P, Ward S, Carlsen K, et al. Recommendations on the use of exercise testing in clinical practice. Eur Respir J. 2007;29 (1):185-209. doi:10.1183/09031936.00046906

110. Perrault H, Baril J, Henophy S, Rycroft A, Bourbeau J, Maltais F. Paced-walk and step tests to assess exertional dyspnea in COPD. COPD. 2009;6(5):330-339. doi:10.1080/15412550903156317

111. O'Donnell DE, Maltais F, Porszasz J, et al. The continuum of physiological impairment during treadmill walking in patients with mild-to-moderate COPD: patient characterization phase of a randomized clinical trial. PLoS One. 2014;9(5):e96574. doi:10.1371/journal.pone.0096574

112. Lewthwaite H, Li PZ, O'Donnell DE, Jensen D. Multidimensional breathlessness response to exercise: impact of COPD and healthy ageing. Respir Physiol Neurobiol. 2021;287:103619. doi:10.1016/j.resp.2021.103619

113. Faisal A, Alghamdi BJ, Ciavaglia CE, et al. Common mechanisms of dyspnea in chronic interstitial and obstructive lung disorders. Am J Respir Crit Care Med. 2016;193(3):299-309. doi:10.1164/rccm.201504-0841OC
114. O'Donnell DE, Guenette JA, Maltais F, Webb KA. Decline of resting inspiratory capacity in COPD: the impact on breathing pattern, dyspnea, and ventilatory capacity during exercise. Chest. 2012;141(3):753-762. doi:10.1378/chest.11-0787

115. O'Donnell DE, Travers J, Webb KA, et al. Reliability of ventilatory parameters during cycle ergometry in multicentre trials in COPD. Eur Respir J. 2009;34(4):866-874. doi:10.1183/ 09031936.00168708

116. Mador MJ, Rodis A, Magalang UJ. Reproducibility of Borg scale measurements of dyspnea during exercise in patients with COPD. Chest. 1995;107(6):1590-1597. doi:10.1378/chest.107.6.1590

117. Peters MM, Webb KA, O'Donnell DE. Combined physiological effects of bronchodilators and hyperoxia on exertional dyspnoea in normoxic COPD. Thorax. 2006;61(7):559-567. doi:10.1136/ thx.2005.053470

118. Eves ND, Sandmeyer LC, Wong EY, et al. Helium-hyperoxia: a novel intervention to improve the benefits of pulmonary rehabilitation for patients with COPD. Chest. 2009;135(3):609-618. doi:10.1378/chest.08-1517

119. Abdallah SJ, Wilkinson-Maitland C, Saad N, et al. Effect of morphine on breathlessness and exercise endurance in advanced COPD: a randomised crossover trial. Eur Respir J. 2017;50 (4):1701235. doi:10.1183/13993003.01235-2017

120. O'Donnell DE, Fluge T, Gerken F, et al. Effects of tiotropium on lung hyperinflation, dyspnoea and exercise tolerance in COPD. Eur Respir J. 2004;23(6):832-840. doi:10.1183/ 09031936.04 .00116004

121. O'Donnell DE, Voduc N, Fitzpatrick M, Webb KA. Effect of salmeterol on the ventilatory response to exercise in chronic obstructive pulmonary disease. Eur Respir J. 2004;24(1):86-94. doi:10.1183/09031936.04.00072703

122. Maltais F, Hamilton A, Marciniuk D, et al. Improvements in symptom-limited exercise performance over $8 \mathrm{~h}$ with once-daily tiotropium in patients with COPD. Chest. 2005;128 (3):1168-1178. doi:10.1378/chest.128.3.1168

123. Zhang J, Schaeffer MR, Mitchell RA, et al. A multidimensional assessment of dyspnoea in healthy adults during exercise. Eur $J$ Appl Physiol. 2020;120(11):2533-2545. doi:10.1007/s00421020-04479-2

124. Lewthwaite H, Jensen D. Multidimensional breathlessness assessment during cardiopulmonary exercise testing in healthy adults. Eur J Appl Physiol. 2021;121(2):499-511. doi:10.1007/s00421020-04537-9

125. Neder JA, Berton DC, Nery LE, et al. A frame of reference for assessing the intensity of exertional dyspnoea during incremental cycle ergometry. Eur Respir J. 2020;56(4):2000191. doi:10.1183/ 13993003.00191-2020

126. Tsiligianni I, Kocks JWH. Daytime symptoms of chronic obstructive pulmonary disease: a systematic review. NPJ Prim Care Respir Med. 2020;30(1):6. doi:10.1038/s41533-020-0163-5

127. Williams MT, Johnston KN. Multidimensional measurement of breathlessness: recent advances. Curr Opin Support Palliat Care. 2019;13(3):184-192. doi:10.1097/SPC.0000000000000436

128. Mahler DA, Sethi S. Enhanced drug and device development by targeting "Relief of Dyspnea". Chest. 2020;158(2):464-466. doi:10.1016/j.chest.2020.04.040 


\section{Publish your work in this journal}

The International Journal of COPD is an international, peer-reviewed journal of therapeutics and pharmacology focusing on concise rapid reporting of clinical studies and reviews in COPD. Special focus is given to the pathophysiological processes underlying the disease, intervention programs, patient focused education, and self management protocols. This journal is indexed on PubMed Central, MedLine and CAS. The manuscript management system is completely online and includes a very quick and fair peer-review system, which is all easy to use. Visit http://www.dovepress.com/testimonials.php to read real quotes from published authors. 